\title{
SOME AXIOMS FOR CONSTRUCTIVE ANALYSIS
}

\author{
JOAN RAND MOSCHOVAKIS AND GARYFALLIA VAFEIADOU
}

\begin{abstract}
This note explores the common core of constructive, intuitionistic, recursive and classical analysis from an axiomatic standpoint. In addition to clarifying the relation between Kleene's and Troelstra's minimal formal theories of numbers and number-theoretic sequences, we propose some modified choice principles and other function existence axioms which may be of use in reverse constructive analysis.
\end{abstract}

\section{INTRODUCTION}

Constructive mathematics has been described by Richman as mathematics with intuitionistic logic. Recursive, classical and a large part of constructive analysis can all be expressed in the two-sorted language Kleene and Vesley [11] used to axiomatize a significant part of intuitionistic analysis. Beginning with the minimal system $\mathbf{M}$ in which Kleene formalized the theory of recursive partial functionals, a rich collection of recursively axiomatizable theories can be identified and explored.

Our choice of $\mathbf{M}$ as a neutral base theory for reverse constructive analysis is motivated by practical and historical considerations. On the one hand, $\mathbf{M}$ (like the theory EL preferred by Troelstra and van Dalen) is strong enough to guarantee the existence of every provably recursive function without entailing the principle of full countable choice from numbers to numbers accepted by most, but not all, constructivists. Theorems which do not depend essentially on countable choice are thereby distinguished from those which do. And since Troelstra's original formal treatment of intuitionistic mathematics over EL depended explicitly on Kleene's detailed formal development in $\mathbf{M}$ of the theory of recursive functions and functionals, working directly with $\mathbf{M}$ satisfies our sense of the history of the subject.

On the other hand, $\mathbf{M}$ (unlike EL) guarantees that every detachable subset of the natural numbers has a characteristic function. This feature, which we regard as constructively justified, simplifies the statement and comparison of e.g. restricted versions of the fan theorem. In this context we introduce a new axiom schema $\mathrm{CF}_{\mathrm{d}}$ which can be used to establish a precise relationship between $\mathbf{E L}$ and $\mathbf{M}$.

The abbreviations BISH, INT, RUSS and CLASS respectively represent Bishop constructivism, Brouwerian intuitionism, Markov's Russian recursive constructive mathematics, and classical mathematics. They were introduced by Bridges and Richman in [3] and have become standard, as has the Venn diagram suggesting that BISH is contained in each of INT, RUSS and CLASS (no two of which are compatible). Since Bishop and Brouwer accepted the countable axiom of choice, and RUSS included a recursive choice principle, $\mathbf{M}$ can be interpreted as a proper part of each of the main varieties of constructive analysis.

Formal reasoning, softened by the use of informal rigor, provides the certainty demanded by reverse mathematics. Sometimes formalization reveals connections which are not obvious in informal reasoning, and suggests refinements of recognized 
axioms. In what follows we attempt to be sufficiently precise so that a reader with some knowledge of intuitionistic logic could easily fill in the formal details.

\section{Intuitionistic LOGiC AND the USE of FORMAL LANGUAGE}

1.1. Remark on formalization. Contrary to some accounts, Brouwer did not entirely disdain the use of logic as a tool to simplify the communication of mathematical arguments. Rather, he delegated the axiomatization and formalization of intuitionistic logic, arithmetic and analysis to his student Arend Heyting ([7], [5], [6]), who also contributed significantly to the informal development of intuitionistic mathematics. Heyting's treatment of intuitionistic logic and arithmetic facilitated comparison with the corresponding classical theories, but the same was not true of his formalization of intuitionistic analysis.

Following Heyting's example, Kleene's [9] presented intuitionistic first-order logic, and intuitionistic arithmetic $\mathbf{I A}_{0}$ in a language with only the constants $=, 0,{ }^{\prime},+, \cdot$, as subsystems obtained from the corresponding classical theories by weakening the law of double negation $\neg \neg \mathrm{A} \rightarrow \mathrm{A}$ to $\neg \mathrm{A} \rightarrow(\mathrm{A} \rightarrow \mathrm{B})$. To further clarify the relation between intuitionistic and classical mathematics, Kleene and Vesley [11] formalized Brouwer's analysis in a two-sorted extension of the language of arithmetic, with variables over numbers and one-place number-theoretic functions, symbols for $\lambda$-abstraction and function application, and a finite list of mathematical constants. When needed, additional constants could be added to the list, as for the precise formal treatment of recursive functionals in [10].

Troelstra [15] formalized intuitionistic arithmetic HA in a language including a constant for every primitive recursive number-theoretic function, and elementary analysis EL in a two-sorted extension of this language, relying explicitly on [10] for the details of elementary recursion theory. ${ }^{1}$ Troelstra [15] also gave a formal language and axioms for Heyting arithmetic in all finite types $\mathbf{H A}^{\omega}$, extending HA. We restrict ourselves here to the first two types, which are adequate to express a significant part of elementary analysis, with Kleene's finite list of constants for primitive recursive functiona(al)s enumerated in a footnote.

1.2. A two-sorted formal language and logic for intuitionistic analysis. By $\mathcal{L}_{1}$ we mean Kleene and Vesley's two-sorted language, which is suitable for an intuitionistic theory of choice sequences and recursive functionals. $\mathcal{L}_{1}$ has variables $\mathrm{x}, \mathrm{y}, \mathrm{z}, \ldots$, intended to range over natural numbers; variables $\alpha, \beta, \gamma, \ldots$, intended to range over one-place number-theoretic functions (choice sequences); finitely many constants $0,{ }^{\prime},+, \cdot, \mathrm{f}_{4}, \ldots, \mathrm{f}_{\mathrm{p}}$, each representing a primitive recursive function or functional, where $\mathrm{f}_{i}$ has $k_{i}$ places for number arguments and $l_{i}$ places for type-1 function arguments; parentheses indicating function application; and Church's $\lambda$.

The terms (of type 0) and functors (of type 1) are defined inductively as follows. The number variables and 0 are terms. The function variables and each $f_{i}$ with $k_{i}=1, l_{i}=0$ are functors. If $\mathrm{t}_{1}, \ldots, \mathrm{t}_{k_{i}}$ are terms and $\mathrm{u}_{1}, \ldots, \mathrm{u}_{l_{i}}$ are functors, then $\mathrm{f}_{i}\left(\mathrm{t}_{1}, \ldots, \mathrm{t}_{k_{i}}, \mathrm{u}_{1}, \ldots, \mathrm{u}_{l_{i}}\right)$ is a term. If $\mathrm{x}$ is a number variable and $\mathrm{t}$ is a term, then $\lambda$ x.t is a functor. And if $\mathrm{u}$ is a functor and $\mathrm{t}$ is a term, then $(\mathrm{u})(\mathrm{t})$ is a term.

There is one relation symbol $=$ for equality between terms; equality between functors $\mathrm{u}, \mathrm{v}$ is defined extensionally by $\mathrm{u}=\mathrm{v} \equiv \forall \mathrm{x}(\mathrm{u}(\mathrm{x})=\mathrm{v}(\mathrm{x}))$. The atomic formulas of $\mathcal{L}_{1}$ are the expressions $\mathrm{s}=\mathrm{t}$ where $\mathrm{s}, \mathrm{t}$ are terms. Composite formulas

\footnotetext{
${ }^{1} \mathbf{H A}$ is essentially a definitional extension of $\mathbf{I} \mathbf{A}_{0}$. Pp. 26-27 and 73 of [15] describe the dependence of EL on [10]; a self-contained treatment is in [17], pp. 152-160.
} 
are defined inductively, using the connectives \&, $\vee, \rightarrow, \neg$, quantifiers $\forall, \exists$ of both sorts, and parentheses (often omitted under the usual conventions on scope).

Using one-place number-theoretic function variables for the choice sequences makes intuitionistic analysis expressible in the same language as a portion of classical analysis, as Kleene observed. But also, according to which mathematical axioms are present, the sequence variables can be interpreted as ranging over constructive functions (determined by algorithms) instead of choice sequences, facilitating the comparison of various branches of constructive analysis.

The logical basis of each of the axiomatic theories $\mathbf{T}$ we consider in this language will be two-sorted intuitionistic predicate logic, as presented e.g. in [11]. In each case a corresponding classical theory $\mathbf{T}^{\circ}$ is obtained by strengthening the intuitionistic negation axiom schema $\neg \mathrm{A} \rightarrow(\mathrm{A} \rightarrow \mathrm{B})$ to the classical $\neg \neg \mathrm{A} \rightarrow \mathrm{A}$.

\section{Some ESSEntial aXiOMS FOR INTUITIONISTIC ANALYSIS}

2.1. Axioms for two-sorted intuitionistic arithmetic $\mathbf{I A}_{1}$. The weakest theory considered here is a formal system of two-sorted intuitionistic arithmetic $\mathbf{I} \mathbf{A}_{1}$, a conservative extension (in the language $\mathcal{L}_{1}$ ) of the first-order intuitionistic arithmetic $\mathbf{I} \mathbf{A}_{0}$ in [9] based on $=, 0,{ }^{\prime},+, \cdot$. The mathematical axioms of $\mathbf{I} \mathbf{A}_{1}$ are:

(a) The axiom-schema of mathematical induction (for all formulas of $\mathcal{L}_{1}$ ): $\mathrm{A}(0) \& \forall \mathrm{x}\left(\mathrm{A}(\mathrm{x}) \rightarrow \mathrm{A}\left(\mathrm{x}^{\prime}\right)\right) \rightarrow \mathrm{A}(\mathrm{x})$.

(b) The axioms of $\mathbf{I A}_{0}$ for $=, 0,{ }^{\prime},+, \cdot($ axioms $14-21$ on p. 82 of [9]) and the axioms expressing the primitive recursive definitions of the additional function constants $\mathrm{f}_{4}, \ldots, \mathrm{f}_{26}$ given in [11] and [10]. ${ }^{2}$

(c) The open equality axiom: $\mathrm{x}=\mathrm{y} \rightarrow \alpha(\mathrm{x})=\alpha(\mathrm{y})$.

(d) The axiom-schema of $\lambda$-conversion: $(\lambda x \cdot t(x))(s)=t(s)$, where $t(x)$ is a term and $\mathrm{s}$ is free for $\mathrm{x}$ in $\mathrm{t}(\mathrm{x})$.

For readers familiar with [11], $\mathbf{I A}_{1}$ is the subsystem of Kleene and Vesley's "basic system" obtained by omitting the axiom schemas of countable choice and bar induction ( ${ }^{x} 2.1$ and ${ }^{x} 26.3$, respectively).

2.2. Countable function comprehension $\mathbf{A C}_{00}$ !. The minimal system $\mathbf{M}$ of [10] is obtained by adding to $\mathbf{I} \mathbf{A}_{1}$ the axiom schema

$$
\mathrm{AC}_{00} ! \quad \forall \mathrm{x} \exists ! \mathrm{yA}(\mathrm{x}, \mathrm{y}) \rightarrow \exists \alpha \forall \mathrm{xA}(\mathrm{x}, \alpha(\mathrm{x})),
$$

where $\alpha, \mathrm{x}$ are free for $\mathrm{y}$ in $\mathrm{A}(\mathrm{x}, \mathrm{y})$ and the unique existential quantifier $\exists$ !y expresses "there is exactly one y" in $\mathcal{L}_{1}$. We use $\exists$ !yB $(\mathrm{y})$ as an abbreviation for either $\exists \mathrm{yB}(\mathrm{y}) \& \forall \mathrm{y} \forall \mathrm{z}(\mathrm{B}(\mathrm{y}) \& \mathrm{~B}(\mathrm{z}) \rightarrow \mathrm{y}=\mathrm{z})$ or $\exists \mathrm{yB}(\mathrm{y}) \& \forall \mathrm{y} \forall \mathrm{z}(\mathrm{B}(\mathrm{y}) \& \mathrm{~B}(\mathrm{z}) \rightarrow \mathrm{y} \leq \mathrm{z})$. Since $\forall \mathrm{y}(\mathrm{A}(\mathrm{x}, \mathrm{y}) \vee \neg \mathrm{A}(\mathrm{x}, \mathrm{y})) \& \exists \mathrm{yA}(\mathrm{x}, \mathrm{y}) \rightarrow \exists$ ! $\mathrm{y}(\mathrm{A}(\mathrm{x}, \mathrm{y}) \& \forall \mathrm{z}(\mathrm{z}<\mathrm{y} \rightarrow \neg \mathrm{A}(\mathrm{x}, \mathrm{z})))$ and $\exists$ ! $\mathrm{yA}(\mathrm{x}, \mathrm{y}) \rightarrow \forall \mathrm{y}(\mathrm{A}(\mathrm{x}, \mathrm{y}) \vee \neg \mathrm{A}(\mathrm{x}, \mathrm{y}))$ are provable in $\mathbf{I A}_{1}$, the schema $\mathrm{AC}_{00}$ ! (called "non-choice" by Myhill and "unique choice" by many) expresses countable numerical choice for decidable predicates.

$\mathrm{AC}_{00}$ ! also guarantees that every decidable predicate of natural numbers has a characteristic function, since $\mathbf{I} \mathbf{A}_{1}$ proves $(\mathrm{B}(\mathrm{x}) \vee \neg \mathrm{B}(\mathrm{x})) \leftrightarrow \exists$ ! $\mathrm{y} \leq 1(\mathrm{y}=0 \leftrightarrow \mathrm{B}(\mathrm{x}))$. This feature of $\mathbf{M}$ makes it possible to avoid explicit decidability hypotheses

\footnotetext{
${ }^{2} \mathrm{f}_{0}-\mathrm{f}_{3}$ are $0,{ }^{\prime},+, \cdot$ respectively. $\mathrm{f}_{4}(\mathrm{a}, \mathrm{b})=\mathrm{a}^{\mathrm{b}}$ (exponentiation), and $\mathrm{f}_{5}, \ldots, \mathrm{f}_{20}$ represent the primitive recursive function(al)s $a !, a \dot{-} b, \operatorname{pd}(a), \min (a, b), \max (a, b), \overline{s g}(a), s g(a),|a-b|, r m(a, b)$, $[a / b], \Sigma_{y<b} \alpha(y), \Pi_{y<b} \alpha(y), \min _{y \leq b} \alpha(y), \max _{y \leq b} \alpha(y), p_{a}$ (the $a^{t h}$ prime, with $\left.p_{0}=2\right)$, and $(a)_{i}$ (the exponent of $p_{i}$ in the prime factorization of $a$ ) respectively. $\mathrm{f}_{21}(\mathrm{a})=\operatorname{lh}(\mathrm{a})$ represents the number of positive exponents in the prime factorization of $a$. The remaining function constants will be described as needed.
} 
by introducing sequence variables appropriately; sometimes this device reduces a schema to a single formula.

If $\mathrm{E}$ and $\mathrm{F}$ are two schemas, we may say " $\mathrm{F}$ is a constructive consequence of $\mathrm{E}$ " if every instance of $\mathrm{F}$ is derivable in $\mathbf{M}$ from instances of $\mathrm{E}$, and " $\mathrm{E}$ and $\mathrm{F}$ are constructively equivalent" if each is a constructive consequence of the other.

2.3. Digression on "at most one". Because principles with uniqueness play a fundamental role in constructive mathematics, it is important to be clear about the formal treatment of statements like " $A(x)$ holds for at most one $x$." The most straightforward choice seems to be (a) $\forall \mathrm{x} \forall \mathrm{y}(\mathrm{A}(\mathrm{x}) \& \mathrm{~A}(\mathrm{y}) \rightarrow \mathrm{x}=\mathrm{y})$. However, recent work of the Bishop school renders " $A(x)$ holds for at most one $x$ " formally by (b) $\forall \mathrm{x} \forall \mathrm{y}(\mathrm{x} \neq \mathrm{y} \rightarrow \neg \mathrm{A}(\mathrm{x}) \vee \neg \mathrm{A}(\mathrm{y}))$. Although $\mathbf{M}$ proves (b) $\rightarrow$ (a), the two interpretations are not constructively equivalent, as the following example shows.

Example. Consider the formula

$$
\mathrm{A}(\mathrm{x}) \equiv(\mathrm{x}=0 \& \mathrm{P}) \vee(\mathrm{x}=1 \& \neg \mathrm{P}),
$$

where $\mathrm{P}$ is any formula and $\mathrm{x}$ any variable not occurring free in $\mathrm{P}$. We can easily see that for this $\mathrm{A}(\mathrm{x})$, condition (a) holds in $\mathbf{M}$; however, condition (b) entails $\neg \mathrm{A}(0) \vee \neg \mathrm{A}(1)$ and hence $\neg \mathrm{P} \vee \neg \neg \mathrm{P}$, which is unprovable in $\mathrm{M}$ in general. ${ }^{3}$

Observe however that under either of the assumptions $\forall \mathrm{x}(\neg \mathrm{A}(\mathrm{x}) \vee \neg \neg \mathrm{A}(\mathrm{x}))$ or $\exists \mathrm{xA}(\mathrm{x})$, we have $(\mathrm{a}) \leftrightarrow(\mathrm{b})$. Thus either interpretation of "at most one" could be used to unabbreviate the ! in $\mathrm{AC}_{00}$ !.

2.4. Two equivalent reformulations of $\mathbf{A C}_{00}$ !. The minimal formal theory $\mathbf{M}$ entails the countable sequence comprehension schema $\mathrm{AC}_{01}$ !:

$$
\forall \mathrm{x} \exists ! \beta \mathrm{A}(\mathrm{x}, \beta) \rightarrow \exists \alpha \forall \mathrm{xA}(\mathrm{x}, \lambda \mathrm{t} . \alpha((\mathrm{x}, \mathrm{t}))),
$$

where $\alpha, \mathrm{x}$ are free for $\beta$ in $\mathrm{A}(\mathrm{x}, \beta)$, (x,t) abbreviates $2^{\mathrm{x}} \cdot 3^{\mathrm{t}}$, and $\exists ! \beta \mathrm{B}(\beta)$ abbreviates $\exists \beta \mathrm{B}(\beta) \& \forall \beta \forall \gamma(\mathrm{B}(\beta) \& \mathrm{~B}(\gamma) \rightarrow \beta=\gamma)$ where $\beta=\gamma \equiv \forall \mathrm{x} \beta(\mathrm{x})=\gamma(\mathrm{x}){ }^{4}$ Since $\mathbf{I A}_{1}+\mathrm{AC}_{01}$ ! entails $\mathrm{AC}_{00}$ !, it follows that $\mathbf{M}=\mathbf{I} \mathbf{A}_{1}+\mathrm{AC}_{01}$ !.

Another equivalent version of $\mathrm{AC}_{00}$ ! is a least number comprehension principle $\mathrm{AC}_{00}^{\mu}$, efficiently formulated with the help of a modified existential quantifier. Let $\exists^{\mu} \mathrm{yB}(\mathrm{y})$ abbreviate $\exists \mathrm{y}(\mathrm{B}(\mathrm{y}) \& \forall \mathrm{x}<\mathrm{y} \neg \mathrm{B}(\mathrm{x}))$. Then $\mathrm{AC}_{00}^{\mu}$ is the schema

$$
\forall \mathrm{x} \exists^{\mu} \mathrm{yA}(\mathrm{x}, \mathrm{y}) \rightarrow \exists \alpha \forall \mathrm{xA}(\mathrm{x}, \alpha(\mathrm{x})) .
$$

Because $\mathbf{I} \mathbf{A}_{1}$ proves $\exists^{\mu} \mathrm{yB}(\mathrm{y}) \rightarrow \exists ! \mathrm{y}(\mathrm{B}(\mathrm{y}) \& \forall \mathrm{x}<\mathrm{y} \neg \mathrm{B}(\mathrm{x}))$, obviously $\mathbf{M}=\mathbf{I A}_{1}+$ $\mathrm{AC}_{00}^{\mu}{ }^{5}$

\footnotetext{
${ }^{3}$ If we add to $\mathbf{M}$ a continuity principle, say WC!, and take as $\mathrm{P}$ the formula $\exists \mathrm{x} \alpha(\mathrm{x}) \neq 0$, we can prove $\neg \forall \alpha[\neg \exists \mathrm{x} \alpha(\mathrm{x}) \neq 0 \vee \neg \neg \exists \mathrm{x} \alpha(\mathrm{x}) \neq 0]$ (for a similar result see FIM p. 84).

${ }^{4} \mathrm{We}$ observed that the unique existential number quantifier has the property $\mathbf{I A}_{1} \vdash \exists ! \mathrm{yB}(\mathrm{y}) \rightarrow \forall \mathrm{y}(\mathrm{B}(\mathrm{y}) \vee \neg \mathrm{B}(\mathrm{y}))$ so over $\mathbf{I A}_{1}$ it makes no difference whether the " $\exists$ !y" in $\mathrm{AC}_{00}$ ! is defined using (a) or (b) (see paragraphs 2.2, 2.3 above). The corresponding property for $\exists$ ! $\beta$ fails constructively since $\exists ! \beta \mathrm{A}(\beta) \rightarrow \neg \forall \beta[\mathrm{A}(\beta) \vee \neg \mathrm{A}(\beta)]$ is provable in intuitionistic analysis. Thus it matters how "at most one $\beta$ " is expressed in the formal language.

${ }^{5}$ However, note that $\mathbf{M} \nvdash \exists^{\mu} \mathrm{yB}(\mathrm{y}) \rightarrow \forall \mathrm{y}(\mathrm{B}(\mathrm{y}) \vee \neg \mathrm{B}(\mathrm{y}))$. For a counterexample let $\mathrm{B}(\mathrm{y})$ be $\mathrm{y}=0 \vee(\mathrm{y}=1 \& \mathrm{P})$ where $\mathrm{M} \nvdash \mathrm{P} \vee \neg \mathrm{P}$ and $\mathrm{y}$ is not free in $\mathrm{P}$; cf. $\S 2.3$.
} 
2.5. A characteristic function principle $\mathbf{C F}_{d}$. Consider the following schema, which asserts that every decidable predicate of natural numbers has a characteristic function and is an immediate consequence of $\mathrm{AC}_{00}$ ! over $\mathbf{I} \mathbf{A}_{1}$ :

$$
\mathrm{CF}_{\mathrm{d}} \quad \forall \mathrm{x}(\mathrm{B}(\mathrm{x}) \vee \neg \mathrm{B}(\mathrm{x})) \rightarrow \exists \beta \forall \mathrm{x}[\beta(\mathrm{x}) \leq 1 \&(\beta(\mathrm{x})=0 \leftrightarrow \mathrm{B}(\mathrm{x}))] .
$$

Replacing $\mathrm{AC}_{00}$ ! by $\mathrm{CF}_{\mathrm{d}}$ leads to a proper subsystem $\mathbf{I A}_{1}+\mathrm{CF}_{\mathrm{d}}$ of $\mathbf{M}$.

Theorem 1. $\mathbf{I A}_{1}+\mathrm{CF}_{\mathrm{d}}$ does not prove $\mathrm{AC}_{00}$ !.

Proof. For a classical model of $\mathbf{I A}_{1}+\mathrm{CF}_{\mathrm{d}}$ which fails to satisfy $\mathrm{AC}_{00}$ !, let the sequence variables range over the subclass $\mathcal{P} b$ of $\omega^{\omega}$ consisting of all sequences which are bounded by primitive recursive functions. That is, $\beta \in \mathcal{P} b$ if and only if there is a primitive recursive $\alpha$ such that $\beta \leq \alpha$ (i.e. $\forall x[\beta(x) \leq \alpha(x)]$ ). Using the observation that every primitive recursive functional $\Phi(\alpha, x)=y$ is bounded by a primitive recursive functional (with the same arguments) which is monotone nondecreasing in each argument separately, one can show that $\mathcal{P} b$ is closed under composition and primitive recursion, so under the interpretation each functor $\mathrm{u}$ represents a sequence in $\mathcal{P} b$. The axioms for the function constants, and the axiom schemas for $\forall \alpha$ and $\exists \alpha$, all hold for this reason. The rules of inference and other axioms pose no problem.

The model evidently satisfies $\mathrm{CF}_{\mathrm{d}}$. However, there is an arithmetical formula $\mathrm{A}(\mathrm{x}, \mathrm{y})$ (numeralwise) representing the graph of the Ackermann function, such that $\forall \mathrm{x} \exists$ !yA $(\mathrm{x}, \mathrm{y})$ is provable even in $\mathbf{I A}_{0}$; but the Ackermann function has no primitive recursive bound. So the model fails to satisfy $\mathrm{AC}_{00}$ !.

Proposition 2. Over $\mathbf{I A}_{1}+\mathrm{CF}_{\mathrm{d}}$, the axiom schema $\mathrm{AC}_{00}$ ! is interderivable with the axiom $\forall \rho[\forall \mathrm{x} \exists$ ! $\mathrm{y} \rho((\mathrm{x}, \mathrm{y}))=0 \rightarrow \exists \alpha \forall \mathrm{x} \rho((\mathrm{x}, \alpha(\mathrm{x})))=0]$, where $(\mathrm{x}, \mathrm{y})=2^{\mathrm{x}} \cdot 3^{\mathrm{y}}$.

2.6. Quantifier-free countable choice $\mathbf{Q F}-\mathbf{A C}_{00}$. The quantifier-free axiom of countable choice is the schema $\mathrm{QF}-\mathrm{AC}_{00}$ :

$$
\forall \mathrm{x} \exists \mathrm{yA}(\mathrm{x}, \mathrm{y}) \rightarrow \exists \alpha \forall \mathrm{xA}(\mathrm{x}, \alpha(\mathrm{x})),
$$

where $\mathrm{A}(\mathrm{x}, \mathrm{y})$ is quantifier-free. Predicates with only bounded numerical quantifiers can be reduced to quantifier-free form over $\mathbf{I A}_{1}+\mathrm{QF}-\mathrm{AC}_{00}$ using $\mathrm{f}_{15}$ and $\mathrm{f}_{16}$. Since all quantifier-free formulas are decidable in $\mathbf{I} \mathbf{A}_{1}$, evidently $\mathbf{M}$ proves QF-AC $-C_{00}$. The next two results show that $\mathbf{M}=\mathbf{I A}_{1}+\mathrm{CF}_{\mathrm{d}}+\mathrm{QF}-\mathrm{AC} \mathbf{C}_{00}$, while $\mathbf{I A}_{1}+$ QF-AC $\mathbf{C}_{00}$ (like $\mathbf{I} \mathbf{A}_{1}+\mathrm{CF}_{\mathrm{d}}$ ) is a proper subsystem of $\mathbf{M}$.

Proposition 3. Over $\mathbf{I A}_{1}+\mathrm{CF}_{\mathrm{d}}$, QF-AC $\mathrm{AC}_{00}$ entails $\mathrm{AC}_{00}$ !.

Proof. Assume $(*) \forall \mathrm{x} \exists$ !yA $(\mathrm{x}, \mathrm{y})$. Then $\forall \mathrm{x} \forall \mathrm{y}[\mathrm{A}(\mathrm{x}, \mathrm{y}) \vee \neg \mathrm{A}(\mathrm{x}, \mathrm{y})]$ by the decidability of number-theoretic equality, and so $\forall \mathrm{w}\left[\mathrm{A}\left((\mathrm{w})_{0},(\mathrm{w})_{1}\right) \vee \neg \mathrm{A}\left((\mathrm{w})_{0},(\mathrm{w})_{1}\right)\right]$. Applying $\mathrm{CF}_{\mathrm{d}}$ to this gives $\exists \beta \forall \mathrm{w}\left[\beta(\mathrm{w}) \leq 1 \&\left(\beta(\mathrm{w})=0 \leftrightarrow \mathrm{A}\left((\mathrm{w})_{0},(\mathrm{w})_{1}\right)\right)\right]$, from which (without $\exists \beta$, towards $\exists$-elimination) and $(*): \forall \mathrm{x} \exists \mathrm{y} \beta((\mathrm{x}, \mathrm{y}))=0$. Hence by QF-AC $\mathrm{A}_{00}: \exists \alpha \forall \mathrm{x} \beta((\mathrm{x}, \alpha(\mathrm{x})))=0$ and finally $\exists \alpha \forall \mathrm{xA}(\mathrm{x}, \alpha(\mathrm{x}))$.

Theorem 4. IA $\mathbf{A}_{1}+$ QF-AC $\mathrm{C}_{00}$ does not prove $\mathrm{CF}_{\mathrm{d}}$.

Proof. There is a classical model of $\mathbf{I A}_{1}$ in which the sequence variables are interpreted as ranging over all general recursive functions of one variable, in which $\mathrm{QF}-\mathrm{AC}_{00}$ is true. But this is not a model of $\mathbf{M}$, since $\mathrm{AC}_{00}$ ! with classical logic gives the existence of nonrecursive sequences.

2.7. Comparison with Troelstra's EL. EL is the basic theory for elementary analysis defined in [17] (p. 144) and [15] (p. 72). One difference between Kleene's minimal system $\mathbf{M}$ and Troelstra's $\mathbf{E L}$ is that $\mathbf{M}$ assumes the function existence principle $\mathrm{AC}_{00}$ ! while EL has instead $\mathrm{QF}-\mathrm{AC}_{00}$. It turns out that this is their 
only essential difference. Here we announce some results by the second author, establishing that $\mathbf{E L}$ is essentially weaker than $\mathbf{M}$, while $\mathbf{E L}+\mathrm{CF}_{\mathrm{d}}$ is essentially equivalent to $\mathbf{M}$.

The formal theory EL, like $\mathbf{M}$, is based on two-sorted intuitionistic predicate logic, with variables for natural numbers and for one-place number-theoretic functions, a constant denoting function application, Church's $\lambda$, and $=$ for equality of numbers. But, unlike M, EL has as a basis a different system of two-sorted intuitionistic arithmetic $\mathbf{H} \mathbf{A}_{1}$, a conservative extension of first-order intuitionistic arithmetic HA ("Heyting arithmetic"); the language of $\mathbf{H A}$ differs from that of $\mathbf{I} \mathbf{A}_{\mathbf{0}}$ in that it has infinitely many function constants, one for each primitive recursive derivation of a number-theoretic function. In addition, $\mathbf{H} \mathbf{A}_{1}$ has a constant rec which represents the functional corresponding to definition by primitive recursion. Terms and functors are defined as usual, with an additional clause for rec: if $\mathrm{t}, \mathrm{t}^{\prime}$ are terms and $\phi$ a functor then $\operatorname{rec}\left(\mathrm{t}, \phi, \mathrm{t}^{\prime}\right)$ is a term. The open equality axiom $\mathrm{x}=\mathrm{y} \rightarrow \alpha(\mathrm{x})=\alpha(\mathrm{y})$ is treated as part of the logic, and equality between functors is defined extensionally.

The mathematical axioms of $\mathbf{H A}_{1}$ are the axioms of $\mathbf{H A}$, with the schema of mathematical induction for all formulas of the language of $\mathbf{H} \mathbf{A}_{1}$, the axiom-schema of $\lambda$-conversion, and axioms for the recursor constant rec:

$$
\operatorname{REC}\left\{\begin{array}{l}
\operatorname{rec}(\mathrm{t}, \phi, 0)=\mathrm{t}, \\
\operatorname{rec}\left(\mathrm{t}, \phi, \mathrm{S}\left(\mathrm{t}^{\prime}\right)\right)=\phi\left(\left(\operatorname{rec}\left(\mathrm{t}, \phi, \mathrm{t}^{\prime}\right), \mathrm{t}^{\prime}\right)\right),
\end{array}\right.
$$

with $\mathrm{t}, \mathrm{t}^{\prime}$ terms and $\phi$ a functor (where $\mathrm{S}$ is the successor).

EL is obtained by adding QF- $\mathrm{AC}_{00}$ to $\mathbf{H A} \mathbf{A}_{1}$.

Proposition 5. EL $+\mathrm{CF}_{\mathrm{d}}$ proves $\mathrm{AC}_{00}$ !.

Proposition 6. EL does not prove $\mathrm{CF}_{\mathrm{d}}$.

In order to express in an exact way the relationship between the two systems EL and $\mathbf{M}$ we consider particular corresponding extensions $\mathbf{E L}^{+}$and $\mathbf{M}^{+}$; we can then prove that $\mathbf{E L}{ }^{+}+\mathrm{CF}_{\mathrm{d}}$ and $\mathbf{M}^{+}$coincide modulo trivial notational differences.

Theorem 7. (a) $\mathbf{E L}^{+}+\mathrm{CF}_{\mathrm{d}}$ is a conservative extension of $\mathbf{M}$.

(b) $\mathbf{M}^{+}$is a conservative extension of $\mathbf{E L}+\mathrm{CF}_{\mathrm{d}}$.

(c) Every theorem of $\mathbf{E} \mathbf{L}^{+}+\mathrm{CF}_{\mathrm{d}}$ is equivalent (in $\mathbf{E} \mathbf{L}^{+}+\mathrm{CF}_{\mathrm{d}}$ ) to a theorem of $\mathbf{M}$, by a translation, and similarly for $\mathbf{M}^{+}$and $\mathbf{E L}+\mathrm{CF}_{\mathrm{d}}$.

Troelstra ([16] p. 585) mentions (and uses) a result of N. Goodman stating that $\mathbf{E L}_{\mathbf{1}}$ is conservative over $\mathbf{H A}$, where $\mathbf{E L}_{\mathbf{1}}$ is $\mathbf{E L}+\mathrm{AC}_{01}$. It follows a fortiori that $\mathbf{E L}+\mathrm{CF}_{\mathrm{d}}$ is conservative over $\mathbf{H A}$.

Proposition 8. $\mathbf{M}^{+}$is a conservative extension of $\mathbf{H A}$.

Proposition 9. $\mathbf{M}$ is a conservative extension of $\mathbf{I} \mathbf{A}_{\mathbf{0}}$.

Remark. Although EL (or even its subsystem $\mathbf{E L}_{\mathrm{ELEM}}$, in [8]) is often taken as basis for constructive reverse mathematics, most results have been obtained in systems essentially equivalent to $\mathbf{M}$ such as $\mathbf{W K V}$ ([12]) and $\mathbf{E L}+\mathrm{AC}_{00}$ !, or even stronger ones such as $\mathbf{E L}+\mathrm{AC}_{00}$. The formal system BIM proposed by Veldman [18] as a basis for intuitionistic reverse mathematics avoids assuming $\mathrm{CF}_{\mathrm{d}}$ as an axiom schema by defining "decidable set" as "set with a characteristic function." 6

\footnotetext{
${ }^{6}$ For detailed comparisons of all these formal systems we refer to the second author's PhD Thesis, in preparation.
} 


\section{VARiations on COUntable Choice}

Brouwer, Heyting, Bishop and Kleene-Vesley all represented real numbers by Cauchy sequences of (primitive recursive codes for) rational numbers, sometimes specifying a particular rate of convergence. Troelstra and van Dalen ([17] p. 253) require that each Cauchy real be given together with a Cauchy modulus for it. Adding the axiom schema $\mathrm{AC}_{00}$ of countable numerical choice (like $\mathrm{AC}_{00}$ ! but without the !) would guarantee the existence of a Cauchy modulus for each Cauchy sequence of rationals, but either of the apparently weaker schemas $\mathrm{AC}_{00}^{\mathrm{m}}$ and $\mathrm{AB}_{00}$ described below would have the same effect. ${ }^{7}$

3.1. Monotone countable choice. To state the new axiom schema efficiently in a form which makes clear its relation to $\mathrm{AC}_{00}$ ! we introduce a monotone existential quantifier $\exists^{\mathrm{m}}$, where $\exists^{\mathrm{m}} \mathrm{yB}(\mathrm{y})$ abbreviates $\exists \mathrm{yB}(\mathrm{y}) \& \forall \mathrm{y} \forall \mathrm{z}(\mathrm{B}(\mathrm{y}) \& \mathrm{y} \leq \mathrm{z} \rightarrow \mathrm{B}(\mathrm{z}))$. Then $\mathrm{AC}_{00}^{\mathrm{m}}$ is the schema

$$
\forall \mathrm{x} \exists^{\mathrm{m}} \mathrm{yA}(\mathrm{x}, \mathrm{y}) \rightarrow \exists \alpha \forall \mathrm{xA}(\mathrm{x}, \alpha(\mathrm{x})) .
$$

The corresponding principle $\mathrm{AC}_{01}^{\mathrm{m}}$ is

$$
\forall \mathrm{x} \exists^{\mathrm{m}} \beta \mathrm{A}(\mathrm{x}, \beta) \rightarrow \exists \alpha \forall \mathrm{xA}(\mathrm{x}, \lambda \mathrm{t} . \alpha((\mathrm{x}, \mathrm{t}))),
$$

where $\exists \mathrm{m} \beta \mathrm{B}(\beta)$ abbreviates $\exists \beta \mathrm{B}(\beta) \& \forall \beta \forall \gamma(\mathrm{B}(\beta) \& \beta \leq \gamma \rightarrow \mathrm{B}(\gamma))$, where $\beta \leq \gamma$ abbreviates $\forall \mathrm{x} \beta(\mathrm{x}) \leq \gamma(\mathrm{x})$.

Following Vesley's Chapter III of [11], let $\alpha \in \mathbf{R}$ abbreviate

$$
\forall \mathrm{k} \exists \mathrm{x} \forall \mathrm{p} 2^{\mathrm{k}}\left|2^{\mathrm{p}} \alpha(\mathrm{x})-\alpha(\mathrm{x}+\mathrm{p})\right|<2^{\mathrm{x}+\mathrm{p}},
$$

expressing $\forall k \exists x \forall p\left|\frac{\alpha(x)}{2^{x}}-\frac{\alpha(x+p)}{2^{x+p}}\right|<\frac{1}{2^{k}}$. The condition following $\forall k \exists x$ is not monotone in $x$, but $\alpha \in \mathbf{R}$ is easily seen to be equivalent in $\mathbf{M}$ to the formula

$$
\forall \mathrm{k} \exists \mathrm{x} \forall \mathrm{p} \forall \mathrm{q} 2^{\mathrm{k}}\left|2^{\mathrm{p}} \alpha(\mathrm{x}+\mathrm{q})-2^{\mathrm{q}} \alpha(\mathrm{x}+\mathrm{p})\right|<2^{\mathrm{x}+\mathrm{p}+\mathrm{q}}
$$

which Vesley abbreviates by $\alpha \in \mathbf{R}_{\mathbf{1}}$. Then

$\mathbf{M}+\mathrm{AC}_{00}^{\mathrm{m}} \vdash \alpha \in \mathbf{R}_{\mathbf{1}} \rightarrow \exists \beta \forall \mathrm{k} \forall \mathrm{p} \forall \mathrm{q} 2^{\mathrm{k}}\left|2^{\mathrm{p}} \alpha(\beta(\mathrm{k})+\mathrm{q})-2^{\mathrm{q}} \alpha(\beta(\mathrm{k})+\mathrm{p})\right|<2^{\beta(\mathrm{k})+\mathrm{p}+\mathrm{q}}$

since the hypothesis satisfies the monotonicity condition on $\mathrm{x}$.

This example suggests that $\mathrm{AC}_{00}^{\mathrm{m}}$ is not provable in $\mathbf{M}$. Certainly $\mathbf{M}$ does not prove $\exists \mathrm{m} \mathrm{yB}(\mathrm{y}) \rightarrow \forall \mathrm{y}(\mathrm{B}(\mathrm{y}) \vee \neg \mathrm{B}(\mathrm{y}))$ in general, as the following example shows.

Example. Consider the formula $\mathrm{A}(\mathrm{x}) \equiv(\mathrm{x}=0 \& \mathrm{P}) \vee(\mathrm{x}>0)$, where $\mathrm{P}$ is any formula not containing $\mathrm{x}$ free. Clearly $\exists \mathrm{xA}(\mathrm{x})$ and $\forall \mathrm{x} \forall \mathrm{y}(\mathrm{A}(\mathrm{x}) \& \mathrm{x} \leq \mathrm{y} \rightarrow \mathrm{A}(\mathrm{y}))$. Assuming that $\mathbf{M}$ entails the above schema, we get $\forall \mathrm{x}(\mathrm{A}(\mathrm{x}) \vee \neg \mathrm{A}(\mathrm{x}))$ and specializing for $\mathrm{x}=0$ we have $\mathrm{A}(0) \vee \neg \mathrm{A}(0)$, from which follows $\mathrm{P} \vee \neg \mathrm{P}$; but then $\mathbf{M}$ would prove $\mathrm{P} \vee \neg \mathrm{P}$ for any $\mathrm{P}$, which is impossible.

The reader might wonder why we require monotonicity above every instantiation $\mathrm{y}$, in order for $\exists^{\mathrm{m}} \mathrm{yB}(\mathrm{y})$ to hold. One reason is that if $\mathrm{B}(\mathrm{y})$ is decidable then $\exists \mathrm{m} y \mathrm{~B}(\mathrm{y})$ will be formally $\Delta_{2}^{0}$ rather than just $\Sigma_{2}^{0}$. Observe also that with our definition of $\exists^{\mathrm{m}}$, assuming the hypothesis of $\mathrm{AC}_{00}^{\mathrm{m}}$, the conclusion of $\mathrm{AC}_{00}^{\mathrm{m}}$ is equivalent to $\exists \alpha \forall \mathrm{x} \forall \mathrm{y} \geq \alpha(\mathrm{x}) \mathrm{A}(\mathrm{x}, \mathrm{y})$.

\footnotetext{
${ }^{7} \mathrm{~A}$ canonical real number generator is a sequence $\alpha$ such that $\forall x|2 \alpha(x)-\alpha(x+1)| \leq 1$, representing the sequence $\left\{\alpha(n) / 2^{n}\right\}$ of dyadic rationals. Canonical real number generators form a particularly nice spread in which each node but the root has just two or three immediate successors, and Cauchy moduli are needed to show that every real number generator coincides with a canonical one.
} 
3.2. Bounded countable choice and a bounding axiom. Countable choice can be weakened either by strengthening the hypothesis by bounding the search, as in the schema $\mathrm{BC}_{00}$ with $\beta$ free:

$$
\forall \mathrm{x} \exists \mathrm{y} \leq \beta(\mathrm{x}) \mathrm{A}(\mathrm{x}, \mathrm{y}) \rightarrow \exists \alpha \forall \mathrm{xA}(\mathrm{x}, \alpha(\mathrm{x})),
$$

or by weakening the conclusion to provide a bound, rather than an exact choice. The second alternative is expressed by the schema $\mathrm{AB}_{00}$ :

$$
\forall \mathrm{x} \exists \mathrm{yA}(\mathrm{x}, \mathrm{y}) \rightarrow \exists \beta \forall \mathrm{x} \exists \mathrm{y} \leq \beta(\mathrm{x}) \mathrm{A}(\mathrm{x}, \mathrm{y}) .
$$

Evidently, $\mathrm{AC}_{00}$ is constructively equivalent to $\mathrm{AB}_{00}+\mathrm{BC}_{00}$, while $\mathbf{M}+\mathrm{AB}_{00}$ proves that every Cauchy sequence of reals has a Cauchy modulus.

Proposition 10. $\mathbf{I A}_{1}+\mathrm{BC}_{00}$ proves $\mathrm{CF}_{\mathrm{d}}$, so $\mathbf{M} \subseteq \mathbf{I A}_{1}+\mathrm{QF}-\mathrm{AC}_{00}+\mathrm{BC}_{00}$.

Proposition 11. $\mathbf{I A}_{1}+\mathrm{BC}_{00}$ does not prove $\mathrm{AB}_{00}$ or $\mathrm{QF}-\mathrm{AC}_{00}$.

Proof. The model used to prove Theorem 1 also establishes this result.

Proposition 12. $\mathbf{I A}_{1}+\mathrm{AB}_{00}$ proves $\mathrm{QF}-\mathrm{AC}_{00}$, so $\mathbf{M} \subseteq \mathbf{I A}_{1}+\mathrm{CF}_{\mathrm{d}}+\mathrm{AB}_{00}$.

Proof. Assume $\forall \mathrm{x} \exists \mathrm{yA}(\mathrm{x}, \mathrm{y})$ where $\mathrm{A}(\mathrm{x}, \mathrm{y})$ is quantifier-free. A term $\mathrm{t}(\mathrm{x}, \mathrm{y})$ with exactly the same free variables as $\mathrm{A}(\mathrm{x}, \mathrm{y})$ can be constructed (cf. [11] p. 30) such that $\mathbf{I A}_{1} \vdash \forall \mathrm{x} \forall \mathrm{y}[\mathrm{t}(\mathrm{x}, \mathrm{y}) \leq 1 \&(\mathrm{~A}(\mathrm{x}, \mathrm{y}) \leftrightarrow \mathrm{t}(\mathrm{x}, \mathrm{y})=0)]$. Moreover, by $\mathrm{AB}_{00}$ : $\exists \beta \forall \mathrm{x} \exists \mathrm{y} \leq \beta(\mathrm{x}) \mathrm{A}(\mathrm{x}, \mathrm{y})$. Given such a $\beta$, the functor

$$
\mathrm{u}=\lambda \mathrm{x} \cdot \Sigma_{\mathrm{z} \leq \beta(\mathrm{x})} \Pi_{\mathrm{y} \leq \mathrm{z}} \mathrm{t}(\mathrm{x}, \mathrm{y})
$$

satisfies $\forall \mathrm{xA}(\mathrm{x}, \mathrm{u}(\mathrm{x}))$, and so $\exists \alpha \forall \mathrm{xA}(\mathrm{x}, \alpha(\mathrm{x}))$.

Proposition 13. Over $\mathbf{I A}_{1}$ (and hence over $\mathbf{M}$ ), $\mathrm{AC}_{00}^{\mathrm{m}}$ and $\mathrm{AB}_{00}$ are equivalent.

Proof. Evidently $\mathbf{I A}_{1} \vdash \forall \mathrm{x} \exists \mathrm{yA}(\mathrm{x}, \mathrm{y}) \rightarrow \forall \mathrm{x} \exists \mathrm{y} \exists \mathrm{z} \leq \mathrm{yA}(\mathrm{x}, \mathrm{z})$ where $\exists \mathrm{z} \leq \mathrm{yA}(\mathrm{x}, \mathrm{z})$ is monotone in $\mathrm{y}$; hence $\mathbf{I A}_{1}+\mathrm{AC}_{00}^{\mathrm{m}} \vdash \mathrm{AB}_{00}$. And if $\mathrm{A}(\mathrm{x}, \mathrm{y})$ is monotone in $\mathrm{y}$ then (in $\mathbf{I} \mathbf{A}_{1}$ ) the conclusion of $\mathrm{AB}_{00}$ entails the conclusion of $\mathrm{AC}_{00}^{\mathrm{m}}$.

Theorem 14. $\mathbf{M}$ does not prove $\mathbf{B C}_{00}$, so $\mathbf{M}$ is a proper subtheory of $\mathbf{I} \mathbf{A}_{1}+$ $\mathrm{QF}-\mathrm{AC}_{00}+\mathrm{BC}_{00}$.

Proof. One of the many results in S. Weinstein's ingenious investigation [19] of Kripke models for intuitionistic analysis is that $\mathrm{AC}_{00}$ is stronger than $\mathrm{AC}_{00}$ ! over a minimal two-sorted intuitionistic theory. ${ }^{8}$ His proof actually showed that $\mathrm{AC}_{00}$ ! is insufficient to prove a particular closed formula of the form

$\forall \mathrm{x}(\mathrm{A}(\mathrm{x}) \vee \mathrm{B}(\mathrm{x})) \rightarrow \exists \alpha \forall \mathrm{x}(\alpha(\mathrm{x}) \leq 1 \&(\alpha(\mathrm{x})=1 \rightarrow \mathrm{A}(\mathrm{x})) \&(\alpha(\mathrm{x})=0 \rightarrow \mathrm{B}(\mathrm{x})))$,

where $\mathrm{A}(\mathrm{x})$ is $\neg \exists \mathrm{yP}(\mathrm{x}, \mathrm{y}), \mathrm{B}(\mathrm{x})$ is $\neg \exists \mathrm{yQ}(\mathrm{x}, \mathrm{y})$, and $\mathrm{P}(\mathrm{x}, \mathrm{y}), \mathrm{Q}(\mathrm{x}, \mathrm{y})$ are quantifierfree formulas numeralwise expressing (in $\mathbf{M}$ ) recursive relations $P(x, y), Q(x, y)$ such that the sets $\{n \in \omega \mid \exists m \in \omega P(n, m)\}$ and $\{n \in \omega \mid \exists m \in \omega Q(n, m)\}$ are nonempty, disjoint and recursively inseparable. By essentially the same argument, $\mathbf{M}$ does not prove $\mathrm{BC}_{00}$.

The questions whether $\mathbf{M}+\mathrm{AB}_{00}$ proves $\mathrm{BC}_{00}$, and whether $\mathbf{M}+\mathrm{BC}_{00}$ proves $\mathrm{AB}_{00}$, are open.

The arguments in this section have obvious consequences for EL, for example the proof of Proposition 12 establishes that $\mathbf{E L} \subseteq \mathbf{H A}_{1}+\mathrm{AB}_{00}$.

\footnotetext{
${ }^{8}$ Note however that $\mathbf{M}$ does prove $\forall \mathrm{x} \leq \mathrm{n} \exists \mathrm{yA}(\mathrm{x}, \mathrm{y}) \rightarrow \exists \alpha \forall \mathrm{x} \leq \mathrm{nA}(\mathrm{x}, \alpha(\mathrm{x}))$, so finite choice is not an issue.
} 


\section{VARIATIONS ON THE BAR THEOREM}

Brouwer's bar theorem, whose axiomatic character was established in [11], can be stated in various ways, depending on the condition the bar predicate is required to satisfy. Before discussing the constructive versions, it is useful to consider the classical bar theorem $\mathrm{BI}^{\circ}$ :

$$
\forall \alpha \exists \mathrm{xR}(\bar{\alpha}(\mathrm{x})) \& \forall \mathrm{w}(\mathrm{R}(\mathrm{w}) \rightarrow \mathrm{A}(\mathrm{w})) \& \forall \mathrm{w}(\forall \mathrm{sA}(\mathrm{w} *\langle\mathrm{~s}\rangle) \rightarrow \mathrm{A}(\mathrm{w})) \rightarrow \mathrm{A}(\langle\rangle),
$$

where $\mathrm{u}, \mathrm{v}, \mathrm{w}, \mathrm{u}_{0}, \mathrm{v}_{0}, \ldots$ range over (primitive recursive) codes for finite sequences, $\bar{\alpha}(\mathrm{x}+1)$ represents the code for $\alpha(0), \ldots, \alpha(\mathrm{x}),\langle\mathrm{s}\rangle$ represents the code for a oneelement sequence with $\mathrm{s}$ as its element, $\bar{\alpha}(0)=\langle\rangle$ the code 1 for the empty sequence, and $*$ the concatenation operation on sequence codes.

In [11] Kleene provided an example showing that the classical bar theorem entails $\forall \beta(\forall \mathrm{x} \beta(\mathrm{x})=0 \vee \neg \forall \mathrm{x} \beta(\mathrm{x})=0)$ so cannot be an axiom schema of intuitionistic analysis. In its place he proposed four alternate, constructively acceptable forms of bar induction which are interderivable over $\mathbf{M}$ and consistent with continuous and countable choice.

4.1. The bar theorem with a decidable, thin or efficient bar. As an axiom schema for FIM interpreting Brouwer's "Bar Theorem" Kleene chose the schema $\mathrm{BI}_{\mathrm{d}}$ of bar induction with a decidable (detachable) bar:

$$
\begin{aligned}
\forall \alpha \exists \mathrm{xR}(\bar{\alpha}(\mathrm{x})) \& & \forall \mathrm{w}(\mathrm{R}(\mathrm{w}) \vee \neg \mathrm{R}(\mathrm{w})) \\
& \& \forall \mathrm{w}(\mathrm{R}(\mathrm{w}) \rightarrow \mathrm{A}(\mathrm{w})) \& \forall \mathrm{w}(\forall \mathrm{sA}(\mathrm{w} *\langle\mathrm{~s}\rangle) \rightarrow \mathrm{A}(\mathrm{w})) \rightarrow \mathrm{A}(\langle\rangle) .
\end{aligned}
$$

He considered three other versions, which we denote by $\mathrm{BI}$ !, $\mathrm{BI}_{\mu}$ and $\mathrm{BI}_{\mathrm{f}}$. The first two of these, each equivalent to $\mathrm{BI}_{\mathrm{d}}$ over $\mathbf{I} \mathbf{A}_{1}$, are obtained from $\mathrm{BI}_{\mathrm{d}}$ by replacing the hypotheses $\forall \alpha \exists \mathrm{xR}(\bar{\alpha}(\mathrm{x}))$ \& $\forall \mathrm{w}(\mathrm{R}(\mathrm{w}) \vee \neg \mathrm{R}(\mathrm{w}))$ by $\forall \alpha \exists$ !xR $(\bar{\alpha}(\mathrm{x}))$ or $\forall \alpha \exists^{\mu} \mathrm{xR}(\bar{\alpha}(\mathrm{x}))$ respectively. The third version $\mathrm{BI}_{\mathrm{f}}$ is

$\forall \alpha \exists \mathrm{x} \rho(\bar{\alpha}(\mathrm{x}))=0 \& \forall \mathrm{w}(\rho(\mathrm{w})=0 \rightarrow \mathrm{A}(\mathrm{w})) \& \forall \mathrm{w}(\forall \mathrm{sA}(\mathrm{w} *\langle\mathrm{~s}\rangle) \rightarrow \mathrm{A}(\mathrm{w})) \rightarrow \mathrm{A}(\langle\rangle)$, which is equivalent to $\mathrm{BI}_{\mathrm{d}}$ over $\mathbf{M}$ or $\mathbf{I A}_{1}+\mathrm{CF}_{\mathrm{d}}$.

4.2. The monotone bar theorem. Requiring only that the predicate $\mathrm{R}(\bar{\alpha}(\mathrm{x}))$ be monotone in $\mathrm{x}$ increases the strength of the bar theorem over $\mathbf{M}$. Let $\mathrm{BI}_{\mathrm{mon}}$ be

$$
\forall \alpha \exists^{\mathrm{m}} \mathrm{xR}(\bar{\alpha}(\mathrm{x})) \& \forall \mathrm{w}(\mathrm{R}(\mathrm{w}) \rightarrow \mathrm{A}(\mathrm{w})) \& \forall \mathrm{w}(\forall \mathrm{sA}(\mathrm{w} *\langle\mathrm{~s}\rangle) \rightarrow \mathrm{A}(\mathrm{w})) \rightarrow \mathrm{A}(\langle\rangle) .
$$

This schema entails BI! over $\mathbf{M}$ (cf. [11] p. 79), but in order to derive $\mathrm{BI}_{\text {mon }}$ from BI! a weak continuous choice principle is often used. Certainly "Brouwer's Principle for Numbers" ( ${ }^{x} 27.2$ in [11]) suffices, so BI $_{\text {mon }}$ is provable in FIM although FIM $+\mathrm{BI}^{\circ}$ is inconsistent.

The use of continuous choice is obviously not essential, since $\mathrm{BI}_{\text {mon }}$ is classically correct. Alternatively, consider the following monotone choice schema $\mathrm{AC}_{1 / 2,0}^{\mathrm{m}}$ :

$$
\forall \alpha \exists^{\mathrm{m}} \mathrm{yR}(\bar{\alpha}(\mathrm{y})) \rightarrow \exists \sigma \forall \alpha[\exists ! \mathrm{x} \sigma(\bar{\alpha}(\mathrm{x}))=0 \& \forall \mathrm{x}(\sigma(\bar{\alpha}(\mathrm{x}))=0 \rightarrow \mathrm{R}(\bar{\alpha}(\mathrm{x})))] .
$$

Proposition 15. $\mathrm{AC}_{1 / 2,0}^{\mathrm{m}}$ is interderivable with $\mathrm{BI}_{\mathrm{mon}}$ over $\mathbf{M}+\mathrm{AC}_{01}+\mathrm{BI}_{\mathbf{f}}$, where $\mathrm{AC}_{01}$ is the strong countable choice axiom schema included in FIM, like $\mathrm{AC}_{01}$ ! but without the !.

Thus $\mathrm{AC}_{1 / 2,0}^{\mathrm{m}}$, which guarantees that every continuous function has a Cauchy modulus, is correct both classically and intuitionistically. Monotonicity is essential, as we now show. 
4.3. Two essentially nonconstructive, classically correct axiom schemas. The constructive failure of $\mathrm{BI}^{\circ}$ places restrictions on constructive choice. Consider the schema $\mathrm{AC}_{1 / 2,0}^{\circ}$ :

$$
\forall \alpha \exists \mathrm{yR}(\bar{\alpha}(\mathrm{y})) \rightarrow \exists \sigma\left[\forall \alpha \exists ! \mathrm{x} \sigma(\bar{\alpha}(\mathrm{x}))=0 \& \forall \mathrm{u} \in \mathbb{N}^{*}(\sigma(\mathrm{u})=0 \rightarrow \mathrm{R}(\mathrm{u}))\right] .
$$

The classical bar theorem $\mathrm{BI}^{\circ}$ follows constructively from $\mathrm{BI} !+\mathrm{AC}_{1 / 2,0}^{\circ}$, so this choice principle is constructively unacceptable. However, as we see in the next section, the corresponding schema for fans holds in intuitionistic analysis.

Now consider the bounding schema $\mathrm{AB}_{1 / 2,0}^{\circ}$ :

$$
\forall \alpha \exists \mathrm{yR}(\bar{\alpha}(\mathrm{y})) \rightarrow \exists \sigma \forall \alpha[\exists ! \mathrm{x} \sigma(\bar{\alpha}(\mathrm{x}))=0 \& \forall \mathrm{x}(\sigma(\bar{\alpha}(\mathrm{x}))=0 \rightarrow \exists \mathrm{y} \leq \mathrm{xR}(\bar{\alpha}(\mathrm{y})))] .
$$

The classical bar theorem $\mathrm{BI}^{\circ}$ follows constructively from $\mathrm{BI}_{\mathrm{mon}}+\mathrm{AB}_{1 / 2,0}^{\circ}$ so this principle is also constructively unacceptable, although the corresponding schema for fans holds in intuitionistic analysis.

There is, however, a classically and intuitionistically correct choice axiom with the same hypothesis, the schema $\mathrm{AC}_{1 / 2,0}$ :

$$
\forall \alpha \exists \mathrm{yR}(\bar{\alpha}(\mathrm{y})) \rightarrow \exists \sigma \forall \alpha[\exists ! \mathrm{x} \sigma(\bar{\alpha}(\mathrm{x}))>0 \& \forall \mathrm{x} \forall \mathrm{y}(\sigma(\bar{\alpha}(\mathrm{x}))=\mathrm{y}+1 \rightarrow \mathrm{R}(\bar{\alpha}(\mathrm{y})))] .
$$

This is an immediate consequence of Brouwer's Principle for Numbers $\left({ }^{*} 27.2\right.$ in [11]) and is classically equivalent to $\mathrm{AC}_{1 / 2,0}^{\circ}$. Should it be acceptable to a Bishop constructivist who accepts $\mathrm{AC}_{00}$ and $\mathrm{AC}_{01}$ ? Bishop's insistence that every existential assertion should be backed up by an algorithm seems to dictate a positive answer.

\section{VARIATIONS ON THE FAN THEOREM}

A fan is a spread in which only finite branching is allowed. The canonical example is the binary fan, on which this section focuses, just as the preceding section concentrated on the universal spread. The most general classically correct version of Brouwer's Fan Theorem for the binary fan (sometimes called the full fan theorem) is expressed by the schema FT:

$$
\forall \alpha \in 2^{\mathbb{N}} \exists \mathrm{xA}(\bar{\alpha}(\mathrm{x})) \rightarrow \exists \mathrm{y} \forall \alpha \in 2^{\mathbb{N}} \exists \mathrm{x} \leq \mathrm{yA}(\bar{\alpha}(\mathrm{x})) .
$$

FT is a constructive consequence of $\mathrm{BI}^{\circ}$, and is interderivable classically (but not constructively) with the schema KL:

$$
\forall \mathrm{y} \exists \alpha \in 2^{\mathbb{N}} \forall \mathrm{x} \leq \mathrm{yA}(\bar{\alpha}(\mathrm{x})) \rightarrow \exists \alpha \in 2^{\mathbb{N}} \forall \mathrm{xA}(\bar{\alpha}(\mathrm{x}))
$$

expressing König's Lemma for the binary fan.

Adding the hypothesis $\forall \mathrm{w}\left[\mathrm{w} \in 2^{*} \& \mathrm{~A}(\mathrm{w}) \rightarrow \mathrm{A}(\mathrm{w} *\langle 0\rangle) \& \mathrm{~A}(\mathrm{w} *\langle 1\rangle)\right]$ to $\mathrm{FT}$ gives a schema $\mathrm{FT}_{\text {mon }}$ constructively equivalent to $\mathrm{FT}$, because the conclusion of the fan theorem is monotone and $\mathbf{M}$ proves $\forall \alpha \in 2^{\mathbb{N}}[\exists \mathrm{xA}(\bar{\alpha}(\mathrm{x})) \leftrightarrow \exists \mathrm{yB}(\bar{\alpha}(\mathrm{y}))]$ where $\mathrm{B}(\mathrm{w})$ is $\exists \mathrm{u} \leq \mathrm{w} \exists \mathrm{v} \leq \mathrm{w}(\mathrm{A}(\mathrm{u}) \& \mathrm{w}=\mathrm{u} * \mathrm{v})$. Since $\mathrm{FT}_{\text {mon }}$ is a constructive consequence of $\mathrm{BI}_{\mathrm{mon}}$ it follows that, unlike $\mathrm{BI}^{\circ}$, $\mathrm{FT}$ is consistent with continuous choice; in fact, FT is provable in FIM.

Proposition 16. $\mathbf{I A}_{1}+\mathrm{BC}_{00}+\mathrm{FT}$ does not prove $\mathrm{QF}-\mathrm{AC}_{00}$.

Proof. The classical model used to prove Theorem 1 and Proposition 8 satisfies FT.

It follows that $\mathbf{M}$ is not a subtheory of $\mathbf{I} \mathbf{A}_{1}+\mathrm{BC}_{00}+\mathrm{FT}$, and $\mathbf{E L}$ is not a subtheory of $\mathbf{H} \mathbf{A}_{1}+\mathrm{BC}_{00}+\mathrm{FT}$. 
5.1. The decidable fan theorem. The decidable fan theorem $\mathrm{FT}_{\mathrm{d}}$ for the binary fan is the schema

$$
\begin{aligned}
\forall \alpha \in 2^{\mathbb{N}} \exists \mathrm{xR}(\bar{\alpha}(\mathrm{x})) \& \forall \mathrm{w}\left[\mathrm{w} \in 2^{*} \rightarrow(\mathrm{R}(\mathrm{w}) \vee \neg \mathrm{R}(\mathrm{w}))\right] & \\
& \rightarrow \exists \mathrm{y} \forall \alpha \in 2^{\mathbb{N}} \exists \mathrm{x} \leq \mathrm{yR}(\bar{\alpha}(\mathrm{x})),
\end{aligned}
$$

which is constructively equivalent to the single axiom $\mathrm{FT}_{\mathrm{f}}$ :

$$
\forall \alpha \in 2^{\mathbb{N}} \exists \mathrm{x} \rho(\bar{\alpha}(\mathrm{x}))=0 \rightarrow \exists \mathrm{y} \forall \alpha \in 2^{\mathbb{N}} \exists \mathrm{x} \leq \mathrm{y} \rho(\bar{\alpha}(\mathrm{x}))=0
$$

as well as to the schema FT!:

$$
\forall \alpha \in 2^{\mathbb{N}} \exists ! \mathrm{xR}(\bar{\alpha}(\mathrm{x})) \rightarrow \exists \mathrm{y} \forall \alpha \in 2^{\mathbb{N}} \exists \mathrm{x} \leq \mathrm{yR}(\bar{\alpha}(\mathrm{x}))
$$

and the schema $\mathrm{FT}_{\mu}$ :

$$
\forall \alpha \in 2^{\mathbb{N}} \exists^{\mu} \mathrm{xR}(\bar{\alpha}(\mathrm{x})) \rightarrow \exists^{\mu} \mathrm{y} \forall \alpha \in 2^{\mathbb{N}} \exists \mathrm{x} \leq \mathrm{yR}(\bar{\alpha}(\mathrm{x})) .
$$

$\mathrm{FT}_{\mathrm{d}}$ is a constructive consequence of $\mathrm{BI}_{\mathrm{d}}$, but not conversely since the arithmetical functions form a realizability model of $\mathbf{M}+\mathrm{FT}_{\mathrm{d}}$ but not of $\mathbf{M}+\mathrm{BI}_{\mathrm{d}}$ (cf. [11], Theorem $9.13^{\mathrm{c}}$ ).

5.2. Restricted monotone fan theorems and a bounding axiom schema. Recently, Bishop constructivists have explored the reverse mathematics of two additional versions of the fan theorem $\mathrm{FT}_{\mathrm{c}}$ and $\mathrm{FT}_{\Pi_{1}^{0}}$. Each comes by replacing the decidability hypothesis in $\mathrm{FT}_{\mathrm{d}}$ by a monotone hypothesis of a restricted kind, and each has interesting mathematical equivalents. $\mathrm{FT}_{\mathrm{d}}$ is a constructive consequence of $\mathrm{FT}_{\mathrm{c}}$, which is a constructive consequence of $\mathrm{FT}_{\Pi_{1}^{0}}$. Bridges [2] and Diener and Loeb [4] asked which of these consequence relations are strict. Berger [1] showed indirectly that $\mathbf{E L}+\mathrm{FT}_{\mathrm{d}}$ does not prove $\mathrm{FT}_{\mathrm{c}}$, but the question whether $\mathbf{M}+$ $\mathrm{FT}_{\mathrm{d}}$ entails $\mathrm{FT}_{\mathrm{c}}$ remains open.

Over $\mathbf{M}$ we can state each of their new versions as a single axiom with a free sequence variable. Thus $\mathrm{FT}_{\mathrm{c}}$ can be expressed by

$$
\forall \alpha \in 2^{\mathbb{N}} \exists \mathrm{y} \forall \mathrm{u} \in 2^{*} \rho(\bar{\alpha}(\mathrm{y}) * \mathrm{u})=0 \rightarrow \exists \mathrm{y} \forall \alpha \in 2^{\mathbb{N}} \forall \mathrm{z} \rho(\bar{\alpha}(\mathrm{y}+\mathrm{z}))=0 .
$$

Using the convention that $\rho(\mathrm{w}, \mathrm{n})$ abbreviates $\rho((\mathrm{w}, \mathrm{n}))$ where $(\mathrm{w}, \mathrm{n})=2^{\mathrm{w}} \cdot 3^{\mathrm{n}}$, the schema $\mathrm{FT}_{\Pi_{1}^{0}}$ is equivalent over $\mathbf{M}$ to

$$
\begin{aligned}
& \forall \alpha \in 2^{\mathbb{N}} \exists \mathrm{y} \forall \mathrm{n} \rho(\bar{\alpha}(\mathrm{y}), \mathrm{n})=0 \\
& \qquad \begin{aligned}
\& \forall \mathrm{w} \in 2^{*} \forall \mathrm{m}[\rho(\mathrm{w}, \mathrm{n})=0 \rightarrow \rho(\mathrm{w} *\langle 0\rangle, \mathrm{m})=0 \& \rho(\mathrm{w} *\langle 1\rangle, \mathrm{m})=0] \\
\rightarrow \exists \mathrm{y} \forall \alpha \in 2^{\mathbb{N}} \forall \mathrm{n} \rho(\bar{\alpha}(\mathrm{y}), \mathrm{n})=0 .
\end{aligned}
\end{aligned}
$$

Now consider the schema $\mathrm{AB}_{1 / 2,0}^{2^{\mathbb{N}}}$ :

$$
\begin{aligned}
\forall \alpha \in 2^{\mathbb{N}} \exists \mathrm{yR}(\bar{\alpha}(\mathrm{y})) \\
\quad \rightarrow \exists \sigma \forall \alpha \in 2^{\mathbb{N}}[\exists ! \mathrm{x} \sigma(\bar{\alpha}(\mathrm{x}))=0 \quad \& \quad \forall \mathrm{x}(\sigma(\bar{\alpha}(\mathrm{x}))=0 \rightarrow \exists \mathrm{y} \leq \mathrm{xR}(\bar{\alpha}(\mathrm{y})))] .
\end{aligned}
$$

Over $\mathbf{M}$, FT is constructively equivalent to $\mathrm{FT}_{\mathrm{d}}+\mathrm{AB}_{1 / 2,0}^{2^{\mathrm{N}}}$. This equivalence holds locally as well as globally:

Theorem 17. Given any predicate $\mathrm{R}(\mathrm{w})$, if $\mathrm{FT}[\mathrm{R}(\mathrm{w})]$ and $\mathrm{AB}_{1 / 2,0}^{2^{\mathrm{N}}}[\mathrm{R}(\mathrm{w})]$ are the corresponding instances of $\mathrm{FT}$ and $\mathrm{AB}_{1 / 2,0}^{2^{\mathbb{N}}}$ respectively, then $\mathrm{FT}[\mathrm{R}(\mathrm{w})]$ is constructively equivalent to $\mathrm{FT}_{\mathrm{d}}+\mathrm{AB}_{1 / 2,0}^{2^{\mathbb{N}}}[\mathrm{R}(\mathrm{w})]$. 
The local result suggests an indirect way to investigate the possible existence of a hierarchy of Fan Theorems over $\mathbf{M}$, by interpreting e.g. $\mathrm{FT}_{\mathbf{c}}$ and $\mathrm{FT}_{\Pi_{1}^{0}}$ as function existence axioms over $\mathbf{M}+\mathrm{FT}_{\mathrm{d}}$. The global result can be sharpened.

5.3. A choice axiom for the binary fan. Consider the schema $\mathrm{AC}_{1 / 2,0}^{2^{\mathbb{N}}}$ : $\forall \alpha \in 2^{\mathbb{N}} \exists \mathrm{yR}(\bar{\alpha}(\mathrm{y})) \rightarrow \exists \sigma\left[\forall \alpha \in 2^{\mathbb{N}} \exists ! \mathrm{x} \sigma(\bar{\alpha}(\mathrm{x}))=0 \& \forall \mathrm{v} \in 2^{*}(\sigma(\mathrm{v})=0 \rightarrow \mathrm{R}(\mathrm{v}))\right]$. Proposition 18. $\mathbf{M}+\mathrm{FT}$ proves $\mathrm{AC}_{1 / 2,0}^{2^{\mathbb{N}}}$.

Proof. The full fan theorem justifies the following principle of fan induction:

$$
\begin{aligned}
\forall \alpha \in 2^{\mathbb{N}} \exists \mathrm{yR}(\bar{\alpha}(\mathrm{y})) \& \forall \mathrm{u} & \in 2^{*}(\mathrm{R}(\mathrm{u}) \rightarrow \mathrm{A}(\mathrm{u})) \\
& \& \forall \mathrm{u} \in 2^{*}(\mathrm{~A}(\mathrm{u} *\langle 0\rangle) \& \mathrm{~A}(\mathrm{u} *\langle 1\rangle) \rightarrow \mathrm{A}(\mathrm{u})) \rightarrow \mathrm{A}(\langle\rangle) .
\end{aligned}
$$

Apply this with $\exists \sigma\left[\forall \alpha \in 2^{\mathbb{N}} \exists ! \mathrm{x} \sigma(\mathrm{u} * \bar{\alpha}(\mathrm{x}))=0 \quad \& \forall \mathrm{v} \in 2^{*}(\sigma(\mathrm{u} * \mathrm{v})=0 \rightarrow \mathrm{R}(\mathrm{u} * \mathrm{v}))\right]$ as the $\mathrm{A}(\mathrm{u})$ to get the result.

It follows immediately that $\mathrm{FT}$ and $\mathrm{AC}_{1 / 2,0}^{2^{\mathbb{N}}}$ are interderivable over $\mathbf{M}+\mathrm{FT}_{\mathrm{d}}$.

5.4. Weak König's Lemma WKL and two variations. WKL or "Weak König's Lemma," which plays a significant role in reverse constructive mathematics, is the restriction of König's Lemma KL to detachable subtrees of the binary fan. Formally, WKL is obtained from KL by adding a decidability hypothesis so WKL is constructively equivalent to

$$
\forall \mathrm{y} \exists \alpha \in 2^{\mathbb{N}} \forall \mathrm{x} \leq \mathrm{y} \rho(\bar{\alpha}(\mathrm{x}))=0 \rightarrow \exists \alpha \in 2^{\mathbb{N}} \forall \mathrm{x} \rho(\bar{\alpha}(\mathrm{x}))=0 .
$$

Adding a strong uniqueness hypothesis of the form

$$
\& \forall \alpha \in 2^{\mathbb{N}} \forall \beta \in 2^{\mathbb{N}}[\exists \mathrm{x} \alpha(\mathrm{x}) \neq \beta(\mathrm{x}) \rightarrow \exists \mathrm{x} \rho(\bar{\alpha}(\mathrm{x})) \neq 0 \vee \exists \mathrm{x} \rho(\bar{\beta}(\mathrm{x})) \neq 0]
$$

gives a principle WKL! constructively equivalent to $\mathrm{FT}_{\mathrm{d}}$; cf. [14]. ${ }^{9}$

A third version of Weak König's Lemma is strictly intermediate in strength between WKL! and WKL from the constructive standpoint. Let WKL!! be the schema

$$
\begin{aligned}
& \forall \mathrm{y} \exists \alpha \in 2^{\mathbb{N}} \forall \mathrm{x} \leq \mathrm{y} \rho(\bar{\alpha}(\mathrm{x}))=0 \\
& \qquad \begin{aligned}
\& \forall \alpha \in 2^{\mathbb{N}} \forall \beta \in 2^{\mathbb{N}}[\forall \mathrm{x} \rho(\bar{\alpha}(\mathrm{x}))=0 \quad \& \quad \forall \mathrm{x} \rho(\bar{\beta}(\mathrm{x})) & =0 \rightarrow \forall \mathrm{x} \alpha(\mathrm{x})=\beta(\mathrm{x})] \\
& \left.\rightarrow \exists \alpha \in 2^{\mathbb{N}} \forall \mathrm{x} \rho(\bar{\alpha}(\mathrm{x}))=0\right] .
\end{aligned}
\end{aligned}
$$

Evidently WKL constructively entails WKL!!, and WKL!! constructively entails WKL!. Hence WKL!! constructively entails $\mathrm{FT}_{\mathrm{d}}$, but the converse fails.

Proposition 19. $\mathbf{M}+\mathrm{FT}_{\mathrm{d}}$ does not prove WKL!!.

Proof. WKL!! can be shown to be constructively equivalent to the conjunction of the principles $\mathrm{MP}^{\vee}$ and $\neg \neg \mathrm{WKL}$. Every theorem of $\mathbf{M}+\mathrm{FT}_{\mathrm{d}}$ is ${ }^{\mathrm{G}}$ realizable, but $\mathrm{MP}^{\vee}$ is not (cf. [13]).

The method of proof of Proposition 19 actually shows that $\mathbf{M}+\mathrm{BI}_{\mathrm{d}}$ does not prove WKL!!, and an analogous argument using Kleene function realizability

\footnotetext{
${ }^{9}$ For consistency with our definition of " $\exists$ ! $\beta$ " we would like to use double exclamation points here, reserving "WKL!" for the principle with the weaker interpretation of "at most one." But since Bishop constructivists have consistently referred to the principle with the strong uniqueness hypothesis as "WKL!," we use double exclamation points to denote the stronger principle WKL!! with the weaker hypothesis.
} 
shows that $\mathbf{M}+\mathrm{BI}_{\mathrm{d}}+\mathrm{WKL}$ !! does not prove WKL. Complete proofs of these results, and of Theorem 17, are part of a note in preparation by the first author.

All the results in Sections 2.6 and 2.7 are part of the second author's PhD dissertation, in preparation. A further investigation of principles with uniqueness is being undertaken by the second author.

\section{Conclusion}

We have tried to suggest one way of organizing reverse constructive analysis, using a formal framework in which the theory of recursive partial functionals and the intuitionistic theory of real numbers have already been developed in detail. We have also tried to show how this framework relates to the one preferred by Troelstra and used by some practitioners of constructive reverse mathematics. Our aim is to simplify comparison of results among the three main constructive traditions, and also to facilitate comparison with classical reverse mathematics.

\section{Acknowledgments}

We would like to thank the Graduate Program in Logic, Algorithms and Computation $(\mathrm{M} \Lambda \Lambda \mathrm{A})$ in Athens, Greece for bringing us together in this endeavor. The first author also thanks the organizers and participants of the 2010 Chiemsee conference "Constructive Mathematics: Proofs and Computations."

\section{REFERENCES}

1. J. Berger, A separation result for varieties of Brouwer's fan theorem, Proceedings of the 10th Asian Logic Conference, Kobe, Japan (T. Arai et al, ed.), World Scientific, 2010, pp. 85-92.

2. D. Bridges, A reverse look at Brouwer's fan theorem, One hundred years of intuitionism (1907-2007), The Cerisy Conference, Springer, 2008, pp. 316-325.

3. D. Bridges and F. Richman, Varieties of constructive mathematics, Cambridge University Press, 1987.

4. H. Diener and I. Loeb, Sequences of real functions on $[0,1]$ in constructive reverse mathematics, Annals of Pure and Applied Logic 157 (2009), 50-61.

5. A. Heyting, Die formalen regeln der intuitionistischen logik, Sitzber. Preuss. Akad. Wiss. (phys.-math. Klasse), Berlin (1930), 42-56, English trans. in Mancosu, P., From Brouwer to Hilbert, Oxford 1998, 311-327.

6. _ Die formalen regeln der intuitionistischen mathematik II, Sitzber. Preuss. Akad. Wiss. (phys.-math. Klasse), Berlin (1930), 57-71.

7. __ Sur la logique intuitionniste, Bull. Acad. Royale Belgique 16 (1930), 957-963, English trans. by A. Rocha in Mancosu, P., op. cit., 306-310.

8. H. Ishihara, Constructive reverse mathematics: Compactness properties, From Sets and Types to Topology and Analysis: Towards Practicable Foundations for Constructive Mathematics (L. Crosilla and P. Schuster, eds.), Oxford Univ. Press, 2005, pp. 245-267.

9. S. C. Kleene, Introduction to metamathematics, van Nostrand, 1952.

10. Math. Soc., 1969.

11. S. C. Kleene and R. E. Vesley, The foundations of intuitionistic mathematics, especially in relation to recursive functions, North Holland, 1965.

12. I. Loeb, Equivalents of the (weak) fan theorem, Annals of Pure and Applied Logic 132 (2005), $51-66$.

13. J. R. Moschovakis, Can there be no nonrecursive functions, Jour. Symb. Logic 36 (1971), 309-315.

14. H Schwichtenberg, A direct proof of the equivalence between Brouwer's fan theorem and König's lemma with a uniqueness hypothesis, Jour. of Universal Comp. Sci. 11 (2005), 20862095. 
15. A. S. Troelstra, Intuitionistic formal systems, Metamathematical Investigation of Intuitionistic Arithmetic and Analysis (A. S. Troelstra, ed.), Lecture Notes in Math., Springer-Verlag, 1973.

16. Note on the fan theorem, Jour. Symb. Logic 39 (1974), 584-596.

17. A. S. Troelstra and D. van Dalen, Constructivism in mathematics: An introduction, volumes $I$ and II, North-Holland, 1988.

18. W. Veldman, Brouwer's approximate fixed-point theorem is equivalent to Brouwer's fan theorem, Logicism, Intuitionism, and Formalism (S. Lindstrom et al, ed.), Synthese Library 341, Springer Netherlands, 2009, pp. 277-299.

19. S. Weinstein, Some applications of Kripke models to formal systems of intuitionistic analysis, Annals of Math. Logic 16 (1979), 1-32. 